\title{
PELATIHAN DIGITAL MARKETING UNTUK IBU-IBU RUMAH TANGGA DI KECAMATAN GEMPOL, KABUPATEN PASURUAN, PROVINSI JAWA TIMUR
}

\author{
Berkah I. Santoso ${ }^{1 *}$, Prima Mulyasari Agustini ${ }^{2}$, Ari Kurnia ${ }^{2}$ \\ ${ }^{1}$ Program Studi Informatika, Fakultas Teknik dan Ilmu Komputer, \\ ${ }^{2}$ Program Studi IImu Komunikasi, Fakultas Ekonomi dan IImu Sosial, \\ Universitas Bakrie, Indonesia \\ E-mail: berkah.santoso@bakrie.ac.id*,prima.agustini@bakrie.ac.id, ari.kurnia@bakrie.ac.id \\ Received: March 4, 2020 / Revised: December 3, 2020 / Accepted: December 25, 2020 \\ DOI: https://doi.org/10.36782/ijsr.v2i2.24
}

\begin{abstract}
ABSTRAK
Penguatan ekonomi rumah tangga, khususnya pada wilayah pedesaan tentunya menjadi tanggung jawab bersama antara pihak pemerintah melalui program-program pemberdayaan masyarakat desa dan pihak keluarga melalui aktivitas ekonominya. Seringkali ibu rumah tangga sebagai pihak yang melakukan pengelolaan ekonomi rumah tangga memiliki keterbatasan waktu, tenaga dan sumber daya. Sementara pihak suami memiliki tanggung jawab sebagai penopang utama ekonomi rumah tangga. Suami juga memiliki keterbatasan dalam pemenuhan kebutuhan hidup rumah tangga. Salah satu terobosan alternatif untuk memberdayakan ibu rumah tangga adalah dengan menggunakan media digital sebagai media tepat guna sebagai salah satu saluran pemasaran barang atau jasa hasil produksi rumahan, atau sering disebut sebagai digital marketing. Penulis telah memberikan pelatihan digital marketing menggunakan media sosial yang telah terinstalasi pada smartphone peserta di Desa Kejapanan, Kecamatan Gempol, Kabupaten Pasuruan, Provinsi Jawa Timur. Lebih lanjut, pelatihan tersebut ditujukan untuk membangun ibu-ibu rumah tangga yang berjiwa pengusaha kreatif di Desa Kejapanan yang dapat menggunakan media digital marketing untuk mempromosikan produk dan jasa rumah tangga secara mandiri.
\end{abstract}

Kata kunci: Digital, Ekonomi, Ibu-Ibu, Marketing, Rumah Tangga, Smartphone.

\begin{abstract}
Household economics reinforcement, especially in village areas, has become responsibility among government through village community empowerment programs and the family economic activity. Housewives, who were managing household economy, often lack of time, power and resources while managing their household economy. Meanwhile, the husband has main responsibility to support household economy to do their job in earning money. He also has limitation to fulfil household needs. One of the alternative breakthrough to empower housewives is using the digital media as an appropriate media which is one of the goods and services home production marketing channel through digital marketing. The writers has given digital marketing workshop using social media which has been installed in audience's smartphone, in location Kejapanan Village, Gempol, Pasuruan, Jawa Timur to its related purpose. Furthermore, the workshop is aimed to develop creative-entrepreneur housewives in
\end{abstract}


Kejapanan Villages which are able to use digital marketing media for promoting household products and services independently.

Keywords: Digital, Economy, Housewives, Marketing, Smartphone.

\section{PENDAHULUAN}

Banyaknya program terobosan penyelenggara negara dilakukan dalam rangka meningkatkan ketahanan ekonomi masyarakat, penyelamatan lingkungan hidup berikut kualitas pelayanan publik pada masyarakat. Satu diantaranya ditempuh melalui peningkatan kualitas sumber daya manusia masyarakat berikut penggunaan produk-produk olahan makanan maupun minuman. Namun demikian, oleh karena jumlah obyek program yang sangat besar dan tersebar di seluruh tanah air, maka tidaklah mungkin semua obyek terjangkau program pemerintah yang dikhususkan untuk itu. Implementasi kebijakan pemerintah yang memiliki karakteristik seperti itu tidak akan berhasil tanpa didukung berbagai pihak, termasuk masyarakat Perguruan Tinggi. Kegiatan pengabdian kepada masyarakat ini merupakan respon kami, selaku para dosen terhadap kondisi tersebut.

Satu diantaranya yang kini menonjol adalah hambatan yang terkait dengan kurangnya pengetahuan ibu-ibu rumah tangga terhadap digital marketing dengan memanfaatkan media internet untuk memasarkan produk olahan minuman yang diproduksi dari rumah tangga. Agar proses penciptaan ketahanan ekonomi keluarga tersebut dapat berlangsung dengan baik, maka ibu-ibu rumah tangga memerlukan pengetahuan dan tools pendukung untuk digunakan dalam mempromosikan produk olahan minuman dari rumah tangga sekaligus menyehatkan, sebagai alternatif pendapatan keluarga. Didasari kenyataan itulah maka gagasan untuk melaksanakan kegiatan pengabdian kepada masyarakat berupa Pelatihan Digital Marketing untuk ibu-ibu rumah tangga di Desa Kejapanan, Kecamatan Gempol, Kabupaten Pasuruan, Provinsi Jawa Timur, kami lakukan. Pada bagian yang penulis lakukan, diberikan pemaparan strategi jitu digital marketing untuk ibu-ibu rumah tangga calon pengusaha jasa atau barang hasil industri rumah tangga. Tools digital marketing ini merupakan aplikasi yang paling umum digunakan oleh pengguna internet maupun pengguna smartphone untuk melakukan aktivitas menggunakan internet (Susanto, 2017). Semua program tersebut sengaja disajikan dalam satu paket karena fungsi dan cara kerja antar program saling berkaitan. Rangkaian program tersebut dapat bersinergi satu dengan yang lain dalam rangka memenuhi tuntutan kebutuhan promosi produk atau jasa dari industri rumah tangga, terutama dalam rangka membangun ketahanan ekonomi keluarga desa setempat. 


\section{TINJAUAN PUSTAKA}

Industri rumah tangga (Industri Rumahan, IR) melalui pemberdayaan perempuan merupakan salah satu upaya peningkatan taraf ekonomi dan ketahanan ekonomi keluarga yang sudah digalakkan oleh Kementerian Pemberdayaan Perempuan dan Perlindungan Anak (PPPA) sejak tahun 2016 yang lalu (Pinsker, 2018).

Ledakan penggunaan internet yang disertai dengan maraknya penggunaan media sosial merupakan potensi melimpahnya ketersediaan perangkat bantu, pendekatan dan saluran pemasaran untuk produk maupun jasa yang ditawarkan tanpa adanya batasan ruang maupun waktu aktivitas (Wood, 2015).

Fase-fase target digital marketing dalam transaksi produk maupun jasa adalah awareness, consideration, purchase, repeat purchase dan loyalty (Santoso, 2018), seperti terlihat pada Gambar 1.

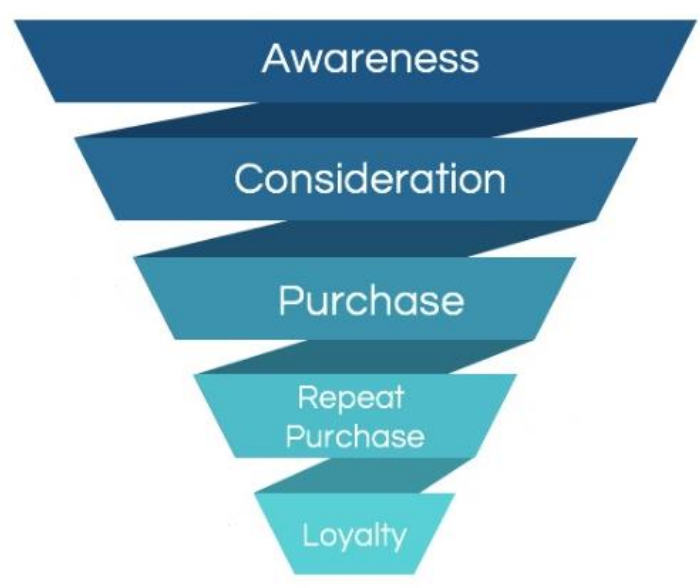

Gambar 1. Customer Buying Path

(Sumber: Santoso, 2018)

Materi Pelatihan Strategi Jitu Digital Marketing (untuk ibu-ibu rumah tangga di pedesaan) ini diarahkan pada pemaparan tips berikut trik-trik terkait penggunaan digital marketing (Santoso, 2018), melalui media internet untuk memasarkan produk maupun jasa (Waringin, 2018), rumah tangga dalam rangka membangun ketahanan ekonomi keluarga (Helianthusonfri, 2018). Digital marketing merupakan alternatif terhadap pemasaran tradisional, dan memiliki kelebihan-kelebihan tertentu dibandingkan pendekatan tradisional (Social and Marketer, 2018).

Penyaji membawakan materi dari tiga pendekatan, yaitu fungsi urgensi, fungsi strategi, dan fungsi praktis (Santoso, 2018), terkait penggunaan digital marketing untuk produk maupun jasa rumah tangga (Susanto, 2017).

\section{TUJUAN PROGRAM}

Kegiatan pengabdian kepada masyarakat ini ditujukan untuk membantu ibu-ibu rumah tangga dalam rangka mengusahakan alternatif pendapatan keluarga dengan memanfaatkan tools digital marketing untuk produk maupun jasa rumah tangga. Terkait dengan misi pengaplikasian pengetahuan yang menjadi tugas dan tanggung-jawab penulis selaku dosen, maka setelah mengikuti kegiatan ini diharapkan peserta pelatihan, yaitu ibu-ibu rumah tangga memiliki pengayaan pengetahuan untuk menggunakan digital marketing sebagai media pemasaran produk maupun jasa rumah tangga (Abadi, 2015). Lebih lanjut kami mengharapkan agar ibu-ibu rumah tangga dapat memiliki 
alternatif pendapatan dengan melakukan kegiatan promosi dan penjualan produk maupun jasa rumah tangga yang mereka hasilkan secara mandiri (Shin, 2018).

Penulis mengharapkan ibu-ibu rumah tangga sebagai pihak yang memiliki peran aktif dalam keluarga dapat melaksanakan peran penting dalam rangka membantu ekonomi keluarga. Mereka secara aktif mulai memasarkan dan melakukan penjualan produk rumah tangga dengan memanfaatkan penggunaan digital marketing melalui media internet via smartphone yang mereka miliki, dimulai dari rumah masing-masing (Su, et.al, 2018).

Kreativitas dan kejelian ibu-ibu rumah tangga dalam menangkap serta memanfaatkan peluang usaha menjadi faktor penentu keberhasilan proses digital marketing produk rumahan yang mereka usahakan (Soerojo, 2019).

\section{METODE DAN MATERI KEGIATAN}

Kegiatan pengabdian kepada masyarakat ini menggunakan 2 (dua) metode, yaitu :

1. Metode pemaparan materi, disampaikan oleh penulis melakukan presentasi langsung kepada peserta yang masing-masing mendapatkan hand out pelatihan digital marketing, dalam hal ini ibu-ibu rumah tangga Desa Kejapanan, Kecamatan Gempol, Kabupaten Pasuruan, Jawa Timur.

2. Metode pemberian contoh digital marketing, dengan memanfaatkan media sosial sebagai contoh aplikasi WhatsApp ${ }^{\circledR}$ messenger untuk memasarkan produk-produk dasar berikut olahan Specialty Arabica Coffee yang telah dirintis oleh penulis sejak 2 (dua) tahun yang lalu, kepada peserta pelatihan.

\section{HASIL DAN PEMBAHASAN}

Kegiatan pelatihan digital marketing untuk ibu-ibu rumah tangga telah berlangsung sesuai dengan jadwal, yaitu pada hari Minggu, 24 November 2019 dilaksanakan pada Desa Kejapanan, Kecamatan Gempol, Kabupaten Pasuruan, Provinsi Jawa Timur. Kegiatan pelatihan digital marketing tersebut diikuti oleh sebanyak 22 (dua puluh dua) ibu-ibu rumah tangga sebagai peserta aktif.

Materi pelatihan yang diberikan meliputi hal-hal sebagai berikut :

1. Mengapa Digital Marketing?

a. Perbedaan Digital vs Traditional Marketing

b. Penting, sebelum memulai digital marketing

c. Keuntungan dan kelemahan digital marketing

d. Pentingnya mengenal fase kampanye digital

2. Praktek Digital Marketing

a. Sebelum ber-digital marketing

b. Ayo ber-digital marketing

Seluruh peserta pelatihan sangat antusias dalam mengikuti proses pelatihan ini. Mereka aktif bertanya mengenai hal-hal yang kurang dipahami dalam pelatihan sehingga 
memudahkan pemateri untuk mengarahkan solusi permasalahan mereka tersebut.

Apabila penulis melihat aktivitas peserta pada kegiatan pengabdian kepada masyarakat tersebut, maka terlihat respons para peserta sangat tinggi, terutama pada saat pelatihan digital marketing dilanjutkan kegiatan praktek pengolahan bahan baku menjadi produk olahan minuman. Banyak diantara mereka yang bertanya dan kemudian terlibat dalam diskusi aktif, baik dengan pemateri maupun sesama peserta lainnya. Antusiasme yang sama ditunjukkan pula pada saat mereka praktik penggunaan tools digital marketing .

Respon dan antusiasme kebanyakan muncul dari peserta yang hanya menggunakan perangkat smartphone untuk bermedia sosial namun masih mengalami kesulitan untuk melakukan digital marketing. Forum pelatihan ini dijadikan ajang untuk bertanya mengenai hal-hal yang sifatnya detail dan teknis. Antusiasme peserta serta interaksinya dengan pemateri bisa dilihat dalam dokumentasi Gambar 2 hingga Gambar 4 sebagaimana berikut.

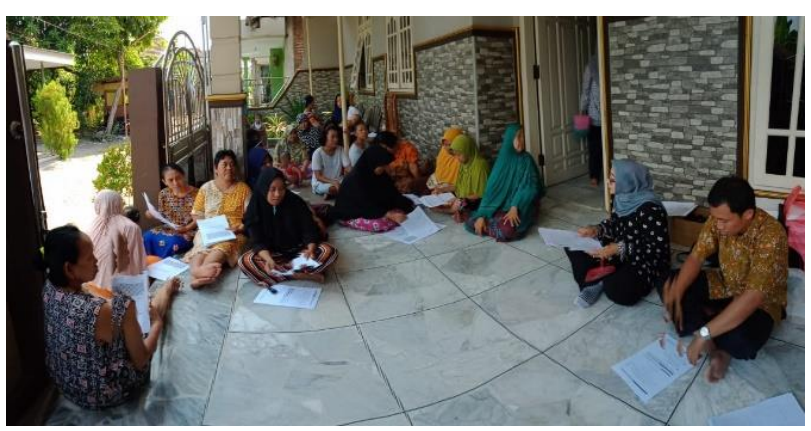

Gambar 2. Sesi pelatihan digital marketing (Sumber: dokumentasi penulis)



Gambar 3. Tim dosen pelaksana pengabdian kepada masyarakat

(Sumber: dokumentasi penulis)



Gambar 4. Foto bersama antara tim dosen pelaksana pengabdian kepada masyarakat dengan peserta yaitu ibu-ibu rumah tangga Desa Kejapanan, Kec.

Gempol

(Sumber: dokumentasi penulis)

\section{KENDALA KEGIATAN}

Pada dasarnya pelaksanaan pengabdian kepada masyarakat berlangsung dengan lancar. Namun apabila ditelaah lebih lanjut, maka masih terdapat beberapa hal yang masih dapat ditingkatkan lebih baik lagi untuk meraih hasil yang lebih optimal. Hal-hal tersebut terangkum pada uraian sebagai berikut:

a. Ketersediaan alat; masalah yang seringkali muncul pada pelatihan berbasis perangkat yang terhubung ke internet adalah keterbatasan alat berupa hardware dan software pendukung. Masing-masing peserta membawa smartphone mereka, rata-rata berbasis sistem operasi Android. Kondisi ini mempengaruhi efisiensi waktu dan efektivitas pelaksanaan pelatihan ini. 
Sehingga dalam menghadapi kondisi ini penulis dituntut untuk lebih sabar dalam memberikan paparan materi dan lebih antusias dalam menghadapi para peserta.

b. Ketersediaan jaringan internet; lokasi kegiatan yang berada pada area pedesaan berakibat pada kurang baiknya kualitas sinyal perangkat komunikasi bergerak seluler. Akibatnya, akses terhadap layanan Internet pun menjadi agak terbatas. Kondisi ini berpengaruh pada komunikasi antar personal, maupun alat bantu pelaksanaan kegiatan yang mungkin dapat diakses melalui Internet. Oleh karena itu pelatihan tools pendukung untuk digital marketing ini belum dapat dilaksanakan secara lengkap.

c. Keberagaman pengetahuan dan kemampuan peserta pelatihan; para peserta aktif pelatihan ini ternyata memiliki kemampuan awal yang berbeda-beda. Ada yang sudah berada pada tingkat lanjut (mahir) dan ada pula peserta yang masih berada pada tingkat dasar. Kebanyakan di antara mereka memiliki pengetahuan yang masih dasar, bahkan ada di antara mereka yang masih sangat awam. Kondisi ini akan mempengaruhi efisiensi waktu dan efektivitas pelaksanaan pelatihan ini. Instruktur dituntut untuk lebih sabar dan memperlakukan para peserta kasus per kasus. Metode pengajaran klasikal yang dirancang untuk pelatihan ini pada praktiknya tidak dapat diterapkan secara massal, tergantung dari motivasi peserta pelatihan.

\section{CAPAIAN KEGIATAN}

Adapun capaian kegiatan yang dilakukan penulis berupa pelatihan bertema digital marketing untuk ibu-ibu rumah tangga Desa Kejapanan, Kecamatan Gempol, Kabupaten Pasuruan, Provinsi Jawa Timur adalah bertambahnya wawasan peserta yang hadir untuk lebih memanfaatkan media sosial sebagai alat bantu pemasaran hasil produk barang maupun jasa rumah tangga.

\section{SUSTAINABILITY KEGIATAN}

Kegiatan bertema digital marketing untuk ibu-ibu rumah tangga akan menjadi lebih terasa manfaat ekonominya apabila dipraktekkan langsung oleh peserta. Praktek langsung digital marketing sebaiknya tidak terbatas pada waktu pelatihan singkat saja. Penulis mengharapkan peserta menetapkan kapasitas produksi dan target penjualan agar tujuan pelatihan menjadi efektif. Program konsultasi pekanan melalui media sosial juga dapat dilakukan untuk memonitor perkembangan peserta pelatihan.

\section{KESIMPULAN}

Pada kegiatan pengabdian kepada masyarakat, penulis telah memberikan pelatihan dengan tema digital marketing untuk ibu-ibu rumah tangga Desa Kejapanan, Kecamatan Gempol, Kabupaten Pasuruan, Provinsi Jawa 
Timur berupa pengayaan pengetahuan mengenai pemanfaatan media sosial sebagai alat bantu pemasaran hasil produk barang maupun jasa rumah tangga.

\section{SARAN}

Pada kegiatan pengabdian kepada masyarakat dalam rangka penyelenggaraan pelatihan strategi jitu digital marketing untuk ibu-ibu rumah tangga desa setempat semacam ini harus dilakukan secara lebih selektif dan lebih intensif lagi serta berkesinambungan dalam bentuk pendampingan. Artinya peserta pelatihan tidak boleh terlampau banyak, namun selama proses pelatihan perlu dibantu oleh asisten pemateri. Keterbatasan dana menghalangi keterlibatan mahasiswa dalam kegiatan kali ini, padahal kehadiran mahasiswa ini akan bisa sangat membantu kegiatan pengabdian kepada masyarakat sebagai asisten pemateri.

Untuk mengatasi keterbatasan alat dan jaringan internet pendukung kegiatan ini, bila memungkinkan maka pelaksanaan kegiatan serupa pada masa yang akan datang agar dapat dilengkapi dengan fasilitas komunikasi yang memadai serta perangkat pendukung seperti proyektor mobile. Materi yang disampaikan dalam kegiatan yang sudah dilaksanakan masih terbatas, agar dipertimbangkan untuk melakukan follow up dalam rangka memantau berikut pendampingan sejauh mana materi yang sudah diberikan memberikan pengaruh atau dampak kepada ibu-ibu rumah tangga (terutama dalam kaitannya untuk membangun ketahanan ekonomi keluarga).

\section{UCAPAN TERIMA KASIH}

Penulis mengucapkan terima kasih sebesarbesarnya kepada Lembaga Pengabdian kepada Masyarakat Universitas Bakrie yang telah memberikan dukungan dana demi pelaksanaan kegiatan pengabdian kepada masyarakat.

\section{DAFTAR PUSTAKA}

Abadi, B. (2015). Sell Like a Wolf: Million Dollar Sales Techniques. Jakarta: Elex Media Komputindo.

Helianthusonfri, J. (2018). Tools for Social Media Marketing. Jakarta: Elex Media Komputindo. Marketer. S. (2017, Juni 6). Pengertian Digital Marketing, Kelebihan dan Kelemahannya. Seo Market, Diakses dari https://seomarket. id/pengertian-digital-marketing-kelebihandan-kelemahannya/

Pinsker, Y.L. (2018). Membangun Ketahanan Ekonomi Keluarga Lewat Pemberdayaan Perempuan. Tribun Jogja. Diakses dari http://jogja.tribunnews.com/2018/05/03/m embangun-ketahanan-ekonomi-keluarga-le wat-pemberdayaan-perempuan/

Santoso, A. Fundamental Digital Marketing. Diakses dari https://www.andysantos o.com/category/digital-marketing/

Shin, E. (2018). The Sales Codes: Kitab untuk Para Sales. Jakarta: Alfa Cemerlang Edindo. 
Soerojo, D, Ridwansyah, (2019). A. Sales Susanto, GM. (2017). The Power of Digital Breakthrough: Buku Wajib Orang Sales. Marketing. Jakarta: Elex Media Komputindo. Jakarta: Gramedia Pustaka Utama. Waringin, T.D. (2018). Workless Earnmore.

Su, F.P, Shih, H.C, Lai, K.K. (2018). Social Media Bengkulu: Elmarkazi. Marketing Practice through Facebook: Wood, C. (2015). Marketing Automation: Lesson Taking W Group Education Foundations as learnt so far... . Journal of Direct, Data and an Example. Proceedings of The 2018 Digital Marketing Practice, 16 (4), 251-254. International Conference on Information Management \& Management Science, China: Agustus 2018, 7-12. 